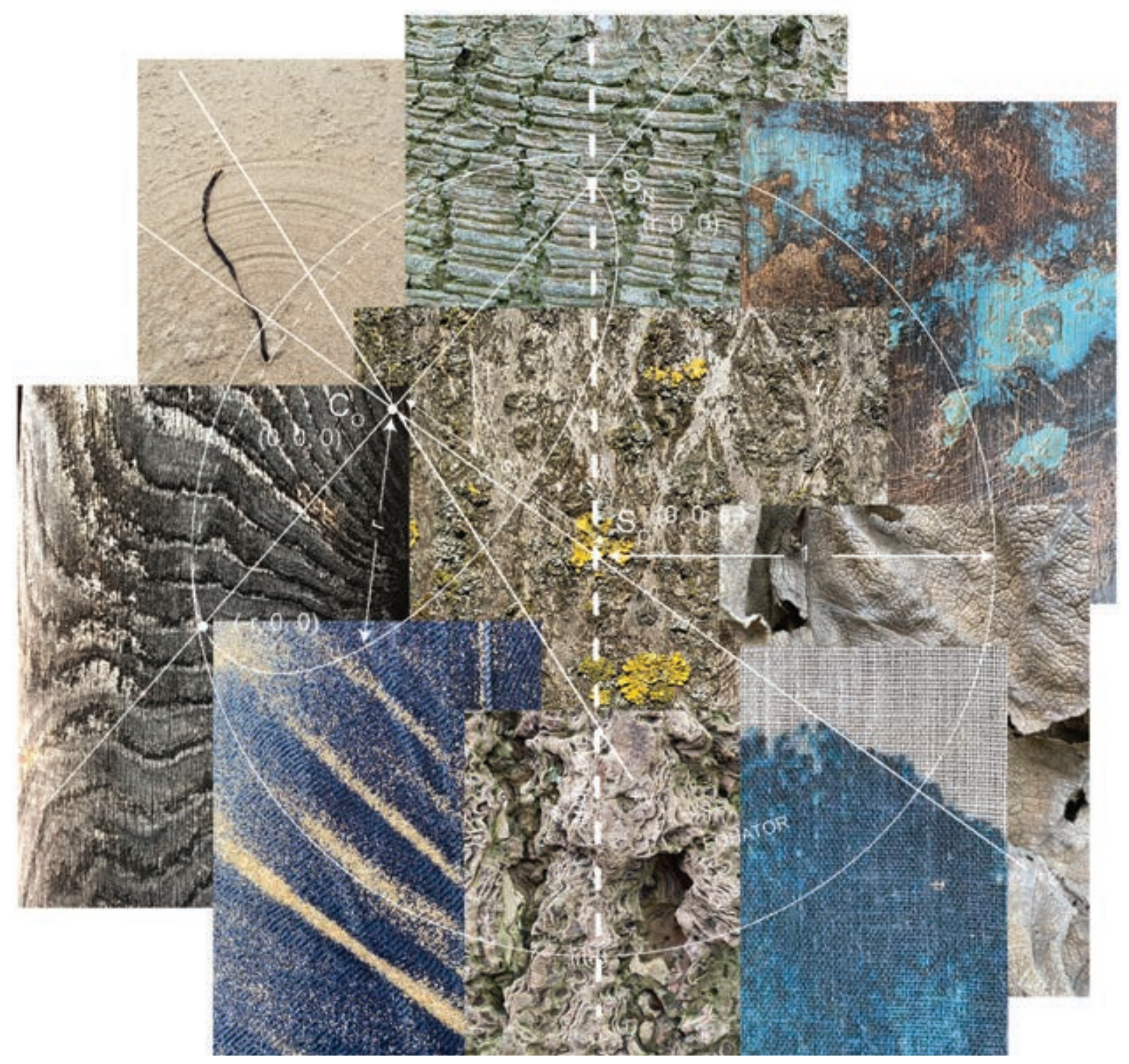




\section{Conscious Material Choices. A Systemic Approach to Reframing our Relationship with Materials and to Accelerating the Positive Impact Future Cristina Freire}

We are immersed in a sustainability crisis fueled by our "take-makewaste" industrial model' and our throwaway culture ${ }^{2}$. We need an urgent, seismic shift from linear growth to sustainable prosperity. Positive impact can be at the core of new ideas, projects and business models, integrating all aspects of sustainability and creating tangible, long-lasting value. We can move positive impact front and center in our creative conversations with materials. Using systems thinking, material professionals can imagine a 'new normal'. Leverage points to activate change include a reframed relationship with materials, a new modus operandi and new opportunities leveraging on circularity thinking and technology. Beyond the immediate opportunities that making conscious material choices can unlock in products and buildings, we can radically accelerate the positive impact future.

\section{KEYWORDS}

Conscious Material Choices, Systems Thinking, Circular Economy, Sustainability, Positive Impact

PALABRAS CLAVE

Decisiones conscientes sobre materiales, pensamiento sistémico, economía circular, sostenibilidad, impacto positivo

FACING AN

INESCAPABLE

CHALLENGE
Earth Day's $50^{\text {th }}$ anniversary ${ }^{3}$ has found us immersed in a sustainability crisis at a scale like never before: climate emergency, water scarcity, plastic soup, airpocalypse, migration crisis... This crisis did not create itself nor happened overnight. It is a consequence of choices. Big, small and in-between choices. Political, corporate and consumers' choices. Incumbents' and newcomers' choices. A complex supra-system of interconnected, inter-dependent choices that shapes our world and exerts more inertia as it carries on.
Cristina Freire Fernández

Master's Degree in Environmental Sciences, Specialty in Environmental Management and Sustainable Development, from the Universidad Autónoma de Madrid, Executive Master's in Environmental Engineering and Management from the EOI Business School and Executive Leadership Program from the THNK School of Creative Leadership in Amsterdam. Cristina has 20 years of experience in sustainability with a focus on energy transition, waste management, design for circularity and future-proof cities. She founded TheNext Sustainability, where she designs and implements sustainability innovation frameworks, carbon-neutrality roadmaps, circularity strategies and positive impact approaches for corporate environments, public bodies and start-ups. She also conducts training sessions and workshops on corporate social responsibility, circularity and positive impact topics.

E-Mail: cristina@thenextsustainability.com
Figs. 01-05

New Lenses, New Cartographies. Lucas Muñoz\&Cristina Freire, 2020. 
Our "take-make-waste" industrial model ${ }^{4}$ and our throwaway culture ${ }^{5}$ inextricably link growth to unsustainability. Science is as unequivocal and irrefutable as ever: our growth-dependent economic system leads to more extreme climate events, less access to water, more pollution and greater inequality in both mature and emerging economies. Our living beyond planetary boundaries already crossed a number of 'tipping points' in the Earth's systems, and greenhouse gas emissions would need to be reduced drastically to avoid the worst impacts 6 . The world is on course to consume as if there were three planet Earths by 2050 .

We are witnessing the consequences of the fundamentally flawed choices of an age of human dominance and hubris over the planet and over everything that lives or exists in it. A growth trap breaking down homeostatic systems and smashing symbiotic connections at every level imaginable.

Another world is possible under different choices. We need an urgent, seismic shift from linear growth to sustainable prosperity, from quantity to value.

HITTING THE RESET BUTTON
Material professionals (designers, architects, artists, engineers...) can collaborate with sustainability, urban and digital innovators and with other voices that are committed to activate change and imagine together a 'new normal'. A reset that fosters wellbeing and regeneration rather than growth and consumption at all costs. Together we can lead the way by enabling new, conscious choices... and by choosing. By prototyping and building with those new choices and by inspiring others to do the same.

Up to $80 \%$ of products' environmental impacts are determined at the design phase ${ }^{8}$. Materials management activities are responsible for two thirds of global carbon emissions ${ }^{9}$. Our material choices have consequences, positive or negative, in the energy use, in the water use and in the health and wellbeing of users of products and buildings. In the immediate term there is a very clear, relevant opportunity for conscious material choices.

Thinking bigger, striving for conscious material choices can spark deeper creative conversations. It can bring forward an alchemical mix of exploration, imagination, serendipity and connection to come up with unique questions and uncommon insights on how to think, build and inspire in entirely new ways so that we can accelerate change.

SETTING POSITIVE IMPACT AS DEFAULT
The concept of eco-design or design for the environment was already around in the 1990s as a strategy to reduce the environmental impacts associated with products and production processes. Designers were embracing a new ethos that pursued a recalibration between human activity and human impact in the natural systems. The Kyoto Protocol, a document setting binding goals for the reduction of greenhouse gas emissions introduced in 1997 and ratified in 2005, identified several challenges where design could have a key contribution ${ }^{10}$ : 
management of human and industrial waste and fostering sustainable

economic growth on a global scale".

This was a call to embrace the roots of design, which started as a system of problem solving, and to minimize negative impacts on both planet and society. A 'doing less harm' approach.

Fast forward to the present day and the concept of 'netzero impact' is front and center in corporate and policy discussions alike. An increasing number of organizations, cities and regions are announcing their commitments to become climate-neutral by 2050 as enshrined in the Paris Agreement", which succeeded the Kyoto Protocol in 2015.

For an increasing number of professionals, organizations and consumers, though, the bar is set higher: the idea of making a positive impact on people, planet and the economy is gaining traction worldwide.

There is an as-yet unexplored potential for positive impact to be at the very core of new ideas, projects and business models. Integrating all aspects of sustainability and focusing on creating, maintaining and distributing value to achieve sustainable prosperity.

The same is true for material choices. We can look at material choices through a broadened lens and aim at accelerating positive impact.

APPLYING

SYSTEMS

THINKING TO

MATERIAL

CHOICES
Systems thinking has been used extensively to address complex problems or to rethink frameworks ${ }^{2}$. Looking through a systemic lens means taking a holistic view, exploring context, discussing boundaries, observing dynamics and deep diving into connections and inter-connections.

Applied to material choices, a systemic approach can help us identify opportunities to simultaneously address different angles and to ripple positive impact through the wider system.

In order to explore how to create the ideal breeding ground for a systemic approach in our creative conversations with materials, we can focus on the following leverage points to activate change:

1. Reframing our relationship with materials; 2 . Embracing a truly collaborative approach; 3 . Drawing upon circularity thinking; 4. Curating positive impact; 5. Leveraging digital technology.

Reframing our relationship with materials
A positive impact approach to material choices transcends the realm of science and can be a wake-up call to rethink our role as humans within the natural systems ${ }^{1314}$. Our 'claim and take' approach to materials is unsound. We have the opportunity to reprogram the equation with an adjusted role for humans, acknowledging that we have been too exclusivist, prescriptive and limiting when determining what value, what meaning and what opportunities do materials present or re-present to the world. In fact, seeing materials through biased eyes has pushed us to relentlessly create new ones to fulfil our needs, our goals and our requirements.

We can engage with materials on different terms.

If we shake off existing connotations associated with materials and go beyond aesthetic, social, environmental and traditional design values, we can broaden and deepen creative conversations with materials and allow for reciprocal exchange and for a truly dynamic system. 
We can acknowledge complexity and uncertainty. We can embrace the coexistence of change -an existing material morphs-, unfolding -a potentiality within an existing material is revealed- and emergence -something new develops ${ }^{-15}$.

We can tap into the wisdom in mimicking nature ${ }^{16}$, finding inspiration in the symbiotic connections and mutually supportive processes that occur in nature ${ }^{17}$.

We can be curious enough, and stubborn enough, to scratch beneath the surface, to get to know more about each material and to understand better the inter-connections with other materials: the obvious and the not-so-obvious, the hidden histories behind, the disparate threads tied together.

We can go beyond specifications, beyond logos, beyond labels. We can hold space for ourselves and for materials. We can have our eyes wide open for uncommon insights, unusual connections and opportunities to create new spaces for material expression.

Maybe we don't choose a material system for positive impact, but we rather allow it to arise ${ }^{18}$.

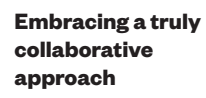
we act systemically. We can leverage collective force and bring information, ideas and critical thinking into creative conversations from many different fields and many different voices. With a both/and perspective instead of an either/or one.

There is no 'one-right-answer'19. Artists, specialists and innovators from the fields of sustainability, digital technologies and urban futures are already collaborating in some creative conversations with material professionals.

When involving these professionals, as well as when considering how and where to look further, the concept of 'neo-generalists' can be particularly inspiring ${ }^{20}$ :

"When the context shifts, so do they. They are fluid and flexible. Their generalist preferences, when combined with what they have experienced through specialist activities, contribute to the development of metaskills: boundary-crossing capabilities that are essential as we respond to big issues or take advantage of unforeseen opportunities.

In network terms, where a specialist can be thought of as living in a node and a generalist occupying a liminal space on the bridges between nodes, the neo-generalist is in flow, constantly moving between bridge and node. They are adaptive, responsive, catalytic".

Neo-generalists can help curate virtuous loops of exploration and learning throughout creative conversations.

We have the opportunity to foster a new modus operandi for conscious material choices beyond negotiating opportunities and trade-offs. We can aim at co-creating solutions that integrate all the voices involved and at making honest, transparent decisions throughout the process ${ }^{21}$.

Setting this collaborative stage at the very beginning of our creative conversations is important. Integrating all the material choices in the design phase can avoid knock-on effects further along in the process and create opportunities to activate change. 


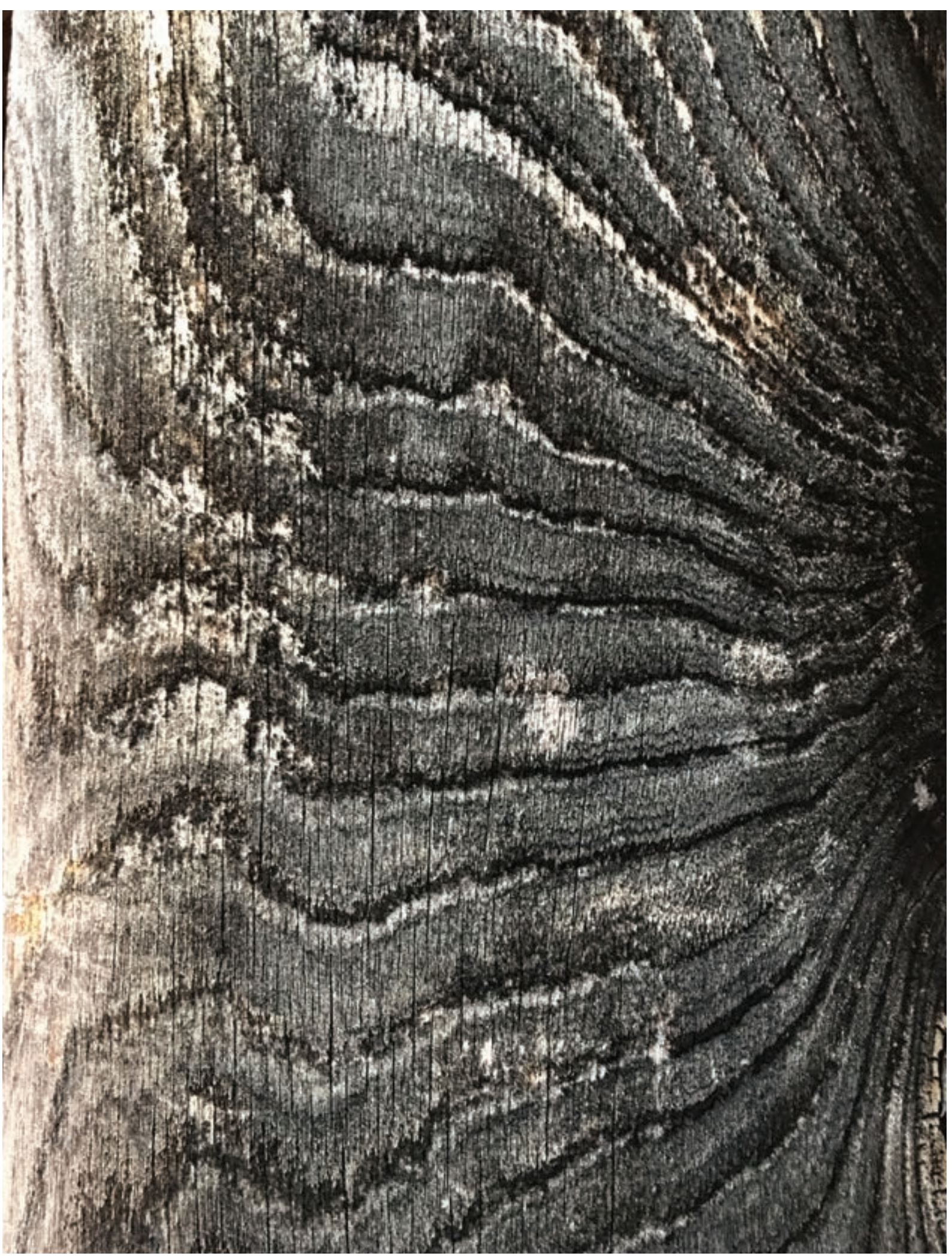




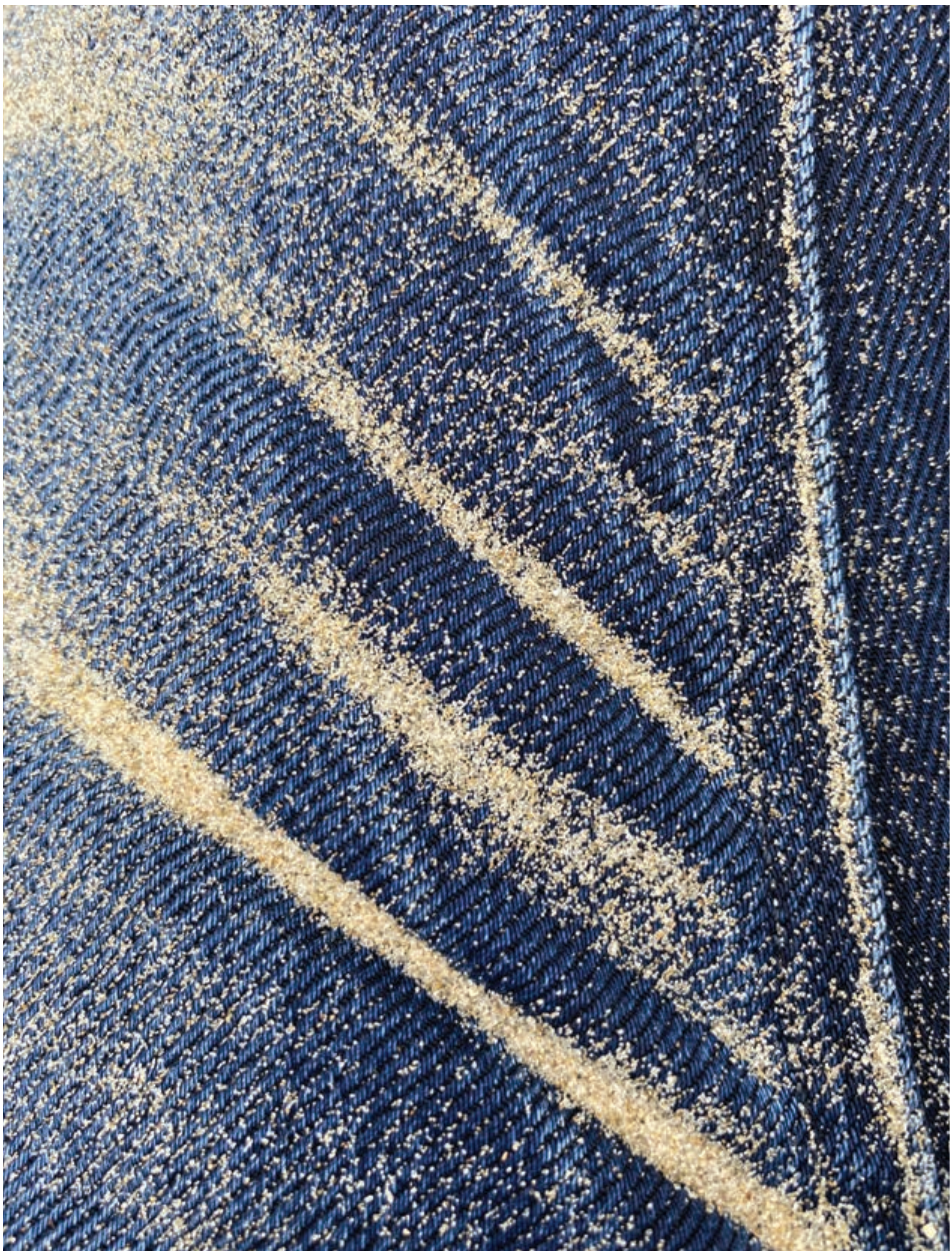


By sparking a shared purpose to unlock positive impact and by staying open to one another's knowledge, experience and unique lens, we will be aligning ourselves with the terms of our reframed relationship with materials.

We can engage with one another on different terms.

We can expand the meaning of material honesty ${ }^{22}$ and expression in the context of creative conversations.

Drawing upon circularity thinking
The circular economy concep $\mathrm{t}^{23}$, also referred to as circularity, has gained incredible momentum in recent years, with the United Nations' Sustainable Development Goals ${ }^{24}$, the Ellen MacArthur Foundation ${ }^{25}$ and Kate Raworth's book Doughnut Economics ${ }^{26}$ driving a global interest in the topic. A circular economy strives to be a 'closed loop system' that builds and maintains value and that is able to "decouple economic growth and development from the consumption of finite resources" ${ }^{27}$. In a circular economy, waste becomes food for the next material loop and consumers become users since "resources are used but not used up" 28 .

This concept builds upon the 'cradle to cradle' design philosophy ${ }^{29}$, which gains insights from living systems, embrace diversity as a driving force in resilient systems, reframe waste as food and shift towards renewable resources ${ }^{30}$.

At the core of circular models is an emphasis on more effective designs that choose and manage materials consciously throughout their lifecycle.

Conscious material choices are essential to mainstream circularity. Designing products or built environments that can be used for a long time and that can be easily taken apart, be recommissioned, remanufactured or refurbished drives circularity, and several circular design strategies are aimed at these goals ${ }^{31}$.

In turn, circularity offers a unique opportunity to creative conversations. An opportunity to explore new paths of creativity, innovation and collaboration. To think in systems and to think in material loops.

An increasing number of projects and initiatives integrates the circularity principles into the design of products, buildings and cities, although this field can still be considered to be at its beginning compared to its potential.

In circular models there are principles, strategies, guidelines and tools that help us identify and assess material choices ${ }^{32}$. But there is no one-size-fits-all approach nor a single pathway towards circularity. There are different starting points, different choices and different journeys. Circularity thinking opens a world of possibilities.

Curating positive impact

As a starting point for creative conversations, it is easy to intuitively feel which is 'the conscious way to go': avoid scarce raw materials and harmful substances, prioritize locally available and already used materials, use only what is needed without wasting raw materials unnecessarily, minimize complex material mixes. When addressing sustainability, it is still common to see siloed approaches focusing on specific material aspects (carbon footprint, recycled content, responsible sourcing ${ }^{33}$...). 
Nonetheless, an increasing number of projects and initiatives are integrating additional aspects and aiming at 'circular' or 'healthy' approaches for materials, products or buildings. They are leveraging on some of the dedicated methodologies, databases and impact assessment tools that are available in the market ${ }^{34}$. These tools can help to analyze, compare and discuss material choices with a common language, thus adding great value to creative conversations. They can also help identify chemicals of concern ${ }^{35,36}$. It is important though to stay connected to a wider approach that seeks to address as many layers of positive impact as possible. There is no one-stop resource for positive impact.

When considering man-made materials, an understanding of why they were created and of the geopolitical, economic and environmental dynamics behind their lifecycle can bring useful insights on opportunities and impacts as well as add some context ${ }^{37}$. Ideas to extend their use or repurpose them are being increasingly explored in products and the built environment ${ }^{38}$ but are far from commonplace. Harmful or potentially harmful chemicals might be present or might be unintentionally released through wear and tear or washing, like in synthetic fibers and textiles. Micro(nano)plastics are a reminder that we lack a holistic understanding about impacts of at least some man-made materials on the natural systems ${ }^{39}$.

It is important to bear in mind that a positive impact choice in one project may have a higher environmental, societal or financial impact in another due to project-specific, location-specific or time-specific circumstances. How to be inclusive also varies in each context. Tailored approaches are required.

Going 'off-road' may be very relevant in a positive impact context. Standard 'off-the-shelf' materials are rarely the only option available. Scouting for experimental ideas, finding inspiration in local or traditional craftmanship, replacing industrial solutions with innovative proposals made by local entrepreneurs or family businesses or combining forgotten materials with technology innovation could all be great opportunities to add new layers to creative conversations.

Leveraging digital technology
Given all the dynamics, angles and voices that a systemic approach encompasses, it becomes especially relevant to explore how digital technologies and tools can help us create new spaces of opportunity.

Blockchain technology and its implications for the concept of digital twins, for example, are addressing a blind spot in conscious material choices: how to reliably and safely keep track and share information about materials as they flow through their lifecycle, from manufacturing to use and to reuse. This requires a vast amount of information, some of which is not readily available or may be protected by intellectual property rights.

Material passports, the most widely used digital twin, are already supporting material decision-making. As part of the European Union's Strategy for Data ${ }^{40}$ announced in February 2020, a common Dataspace for Smart Circular Applications will be established and digital passports will be developed for the built environment providing information about origin, durability, composition and reuse, repair and recycling options. We can explore possibilities to expand this circular focus and 


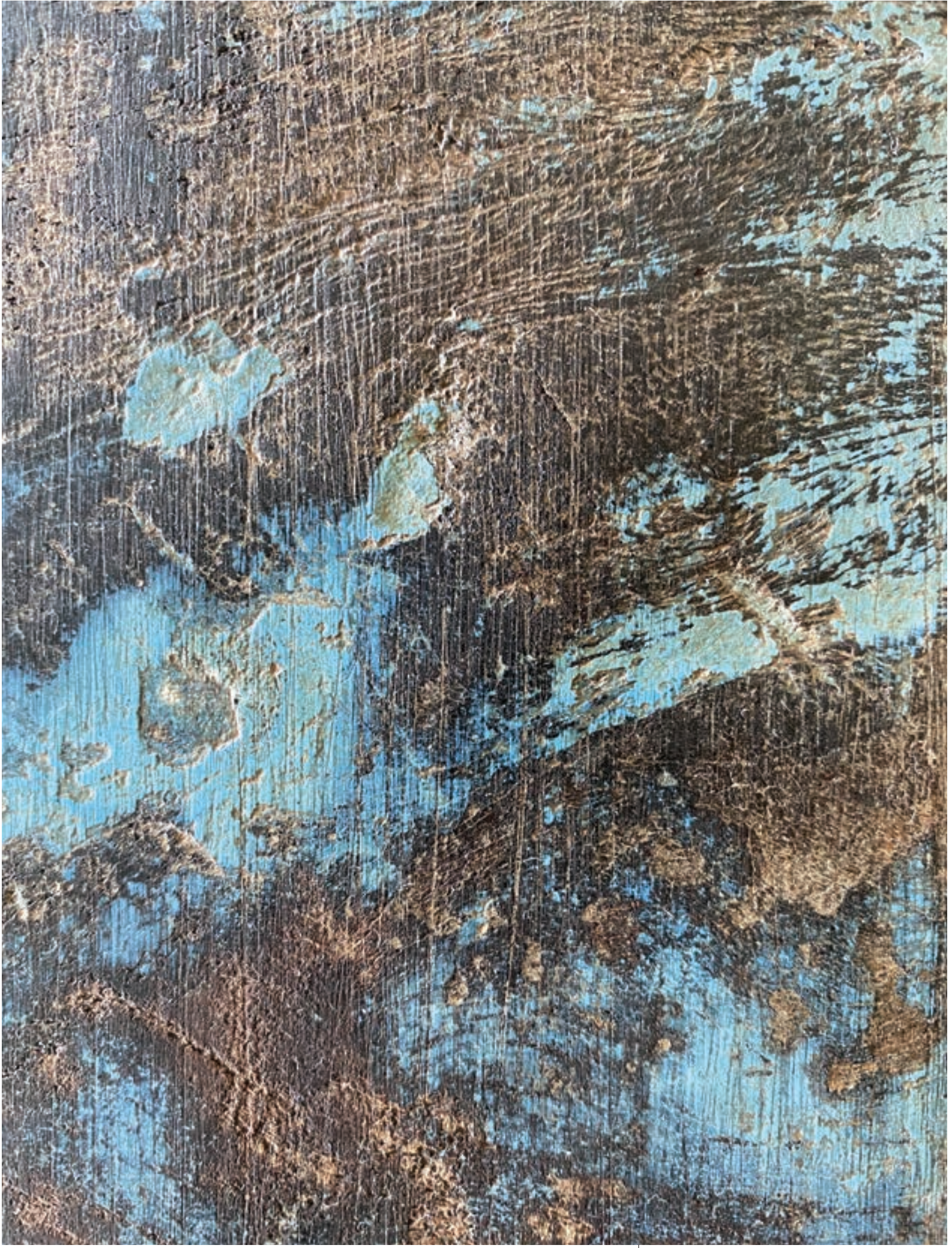


integrate additional layers of positive impact. A holistic approach can unlock the potential of urban mining to revitalize local material loops and value chains and to drive sustainable prosperity ${ }^{41}$.

We will definitely see higher levels of automation in data collection systems through remote sensing, laser scanning or point clouds. As well as new initiatives leveraging on virtual reality, augmented reality and machine learning. Beyond data gathering possibilities, increased automation will allow for new ideas on how to visualize conscious material choices and how to share aspects of our creative conversations with users or with the general public. It will enable new ways to connect, raise awareness and inspire others.

Another boost to conscious material choices will come from digital matching platforms. Collaborative platforms make it easier and more accessible to share, donate, exchange or remarket new or used materials and products. We can explore possibilities of new materials or new options for materials already used by tapping into the potential of existing platforms $\mathrm{s}^{42}$ or by joining forces and creating new materials exchange platforms to drive positive impact further.

ACELERATING CHANGE
The sustainability crisis evidences the delicate inter-connectedness between humans and the natural systems, and the urgency to hit the reset button. A crucial opportunity lies ahead to reimagine our creative conversations and to move positive impact front and center.

By setting new terms for our relationship with materials and for our collaborative creative process, we can explore new meanings for material honesty and material expression.

The lens is wider than the obvious choices and the obvious voices.

By being ambitious, aiming 'always higher', we can continuously integrate more layers of positive impact and be changemakers both locally and globally.

By tapping into circularity thinking and emerging technologies, we can create new spaces of opportunity.

Thinking and acting systemically can help us make conscious material choices that give back more than we take. Beyond the immediate opportunities that are unlocked by conscious material choices, we can radically accelerate the positive impact future. RA 


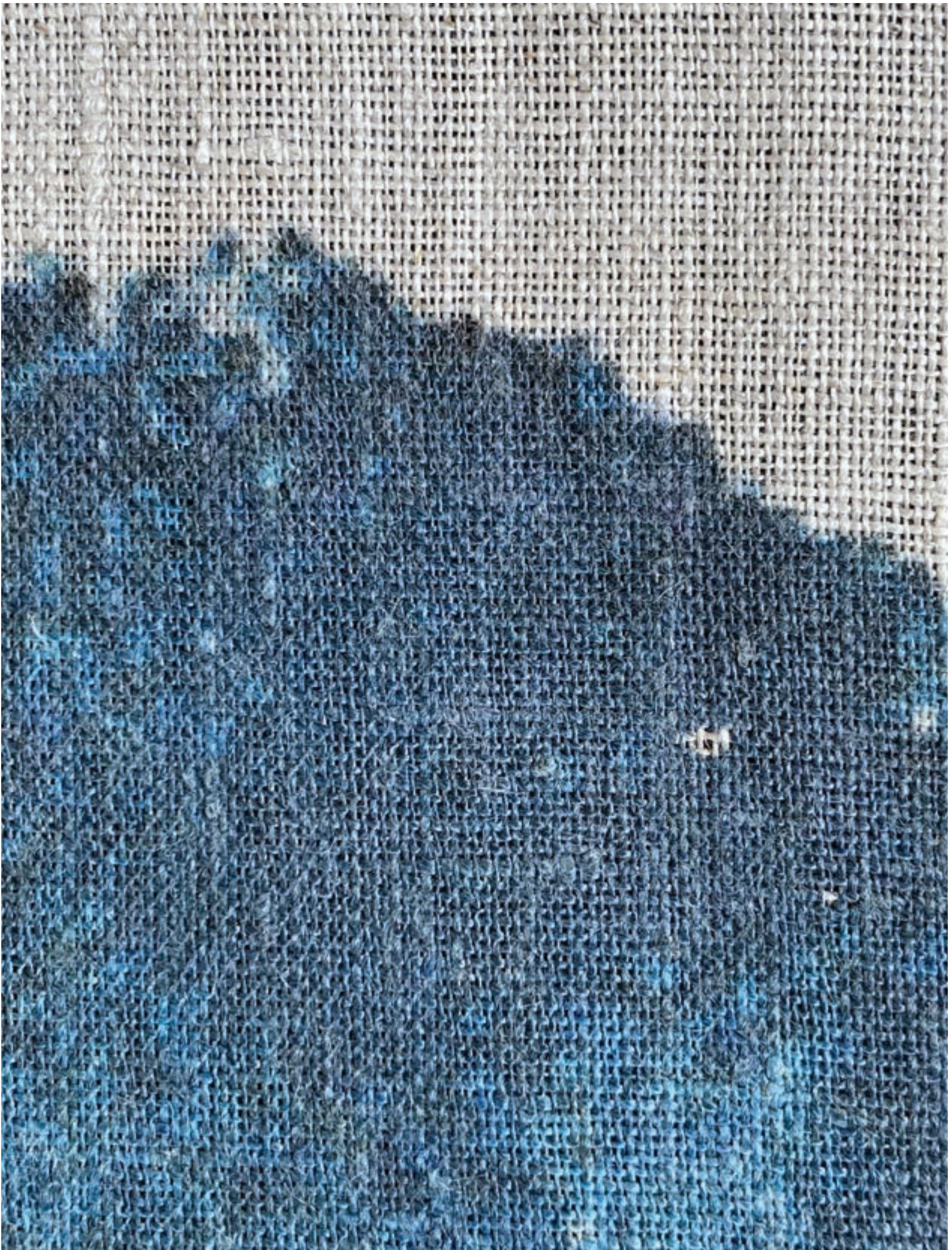


01. WORLD ECONOMIC FORUM, PLATFORM FOR ACCELERATING THE CIRCULAR ECONOMY, Harnessing the Fourth Industrial Revolution for the Circular Economy. Consumer Electronics and Plastic Packaging, Geneva, 2019, p. 7.

02. CATHOLIC CHURCH, MCDONAGH, S., On care for our common home: the encyclical of Pope Francis on the environment, Laudato Si', Vatican City, 2016, p. 6.

03. April 21st, 2020.

04. Ibid. 1.

05. Ibid. 2.

06. UNITED NATIONS, Emissions Gap Report 2019 Global progress report on climate action, UNEP, Nairobi, 2020, p. 15.

\section{EUROPEAN COMMISSION, Circular} Economy Action Plan. For a cleaner and more competitive Europe, Office for Official Publications of the European Communities, Brussels, 2020, p. 4

08. Ibid. 7. p. 6.

09. OECD, Global Material Resources Outlook to 2060: Economic Drivers and Environmental Consequences, OECD Publishing, Paris, 2019, p. 16.

10. KRAMER, $\mathrm{K}$., User Experience in the Age of Sustainability: A Practitioner's Blueprint, Morgan Kaufmann, Burlington, MA, 2012, p. 37.

11. The Paris Agreement calls for urgent action to keep a global temperature rise this century well below 2 degrees Celsius above pre-industrial levels and to pursue efforts to limit the temperature increase even further to 1.5 degrees Celsius.

12. WILLIAMS, A., "Systems thinking: $A$ review of sustainability management research", in Journal of Cleaner Production, 2017, 148, pp. 866-881.

13. HARAWAY, D.J., Staying with the Trouble. Making Kin in the Chthulucene, Duke University Press, Durham and London, 2016, pp. 36-57.

14. MARGULIS, L., SAGAN, D., What is Life?, University of California Press, Berkeley, 1995, pp. 17-18.

15. VAN GEERT, P., "Unfolding potential as dynamic emergence. A view from the theory of complex, non-linear, dynamic systems", in The Journal of Cognitive Education and Psychology 2014, 13, 3, pp. 324-356.

16. SZAKY, T., Outsmart Waste: The Modern Idea of Garbage and How to Think Our Way Out of It, Berrett-Koehler Publishers, San Francisco, 2014, p. 20

17. ŠIJAKOVIĆ, M., "Symbiotic architecture: Redefinition of recycling design principles" in Frontiers of Architectural Research, 2018 7,1, pp. 67-69.

18. Jurgen Hoogendoor (Municipality of Amsterdam) presented the motto of urban innovators DELVA Landscape Architects/ Urbanism, Metabolic and Studioninedots when designing a circular district in Buiksloterham, Amsterdam in 2016 as "you do not design a resilient circular city; you allow it to arise". Extracted from: DELVA LANDSCAPE ARCHITECTS, Circular Cities: designing post-industrial Amsterdam. The case for Buiksloterham, DELVA Landscape Architects, Amsterdam, 2016, p. 7

19. According to legal philosopher Dworkin's right answer thesis from 1985, there is always a right answer as a matter of law that the judge must discover in situations where people's legal rights are controversial.

20. MIKKELSEN, K., MARTIN, R., The NeoGeneralist. Where you go is who you are LID Publishing Ltd., London, 2016, p. 34.

21. An example of a recent project I have collaborated with that aims at such an approach is MO de Movimiento, in Madrid. Creative conversations with project's founder Felipe Turell and project's designer Lucas Muñoz throughout our collaboration have been particularly inspiring.

22. NESBITT, K., Theorizing a new agenda for architecture: an anthology of architectural theory 1965-1995, Princeton Architectural Press, New York, 1996.

23. KORJONEN, J., et al., "Circular Economy: the concept and its limitations" in Ecological Economics, 2018, 143, pp. 37-43.

24. Seventeen Sustainable Development Goals (SDGs) were adopted by all United Nations Member States in 2015 as part of the 2030 Agenda for Sustainable Development are an urgent call for action for all nations to drive peace and prosperity for people and the planet.

25. The Ellen MacArthur Foundation was launched in 2010 to accelerate the transition to a circular economy.
26. RAWORTH, K., Doughnut Economics: Seven Ways to Think Like a 21st-Century Economist, Penguin Random House, London, 2017.

27. WEBSTER, K. The circular economy. A wealth of flows, Ellen MacArthur Foundation Publishing, Cowes, 2015, p. 16.

28. Ibid. 27. p. 19.

29. MCDONOUGH, W., BRAUNGART, M. Cradle to Cradle: Remaking the Way We Make Things, North Point Press, New York, 2002.

30. Ibid. 27. p. 15.

31. BAKKER, C., et al., Products that last: product design for circular business models, TU Delft Library, Delft, 2014, pp. 82-107.

32. Some examples of circular design guidelines and online resources are the collaborative initiatives of the Ellen MacArthur Foundation with IDEO (addressing products), with ARUP (addressing buildings) and with key stakeholders in the textiles value chain (addressing fashion).

33. This is especially relevant for conflict-minerals, cobalt, cotton or wood, for example. Due to high impacts on people and planet, increasing efforts are being deployed by policymakers and corporations towards responsible sourcing including standards.

34. A high-level overview of available methodologies, tools, labels and certifications systems for products and buildings can be found in: $\mathrm{HEINRICH}$, M., LANG, W., Materials Passports: Best Practice Innovative Solutions for a Transition to a Circular Economy in the Built Environment, Technische Universität München, Munich, 2019, pp. 30-43.

35. A high-level overview of chemicals of concern can be found in: $\mathrm{HEINRICH}$, M., LANG, W., Materials Passports: Best Practice Innovative Solutions for a Transition to a Circular Economy in the Built Environment, Technische Universität München, Munich, 2019, p. 13.

36. In some cases it is easy to find 'sustainable' options (for example products with an ecolabel) to purchase or test for a new project, such as paints without Volatile Organic Compounds (VOCs), resins without bisphenol A (BPA) nor formaldehyde or pigments without titanium dioxide. When 


\section{Bibliography}

options are limited, impact assessment tools (see 34) and information in product datasheets can support risk-based assessments in order to minimize impacts.

37. An example of an initiative raising awareness about the value chains of man-made materials and their impacts and opportunities, specifically focusing on synthetic fibers, is the FashionforGood interactive museum in Amsterdam. Polyester, for example, is a synthetic fiber derived from oil that has a high-impact production process and contributes to microplastics pollution. Most polyester currently used in products is virgin polyester due to limitations of recycling. The majority of recycled polyester yarns and fibers in the market come from recycled polyethylene terephthalate (PET), specifically from plastic bottles.

38. An example is Circl, an ABN AMRO pavilion in Amsterdam that has been designed according to the principles of the circular and inclusive economy. The spatial concept focuses on adaptability and showcases some innovative material applications and upcycled or recycled products.

39. HU, D., et al. "Microplastics and nanoplastics: would they affect global biodiversity change?" in Environmental Science Pollution Research, 2019, 26, pp. 19997-20002.

40. EUROPEAN COMMISION, A European strategy for data, Office for Official Publications of the European Communities, Brussels, 2020.

41. The term urban mining is used in this context to refer to the process of recovering materials from products, buildings and/or waste so that they can be used, reused and recycled. As an example, in Europe, the ProSUM project developed a regional, open-access Urban Mine Platform (UMP) and in Amsterdam, the consortium of Leiden University, TU Delft, Waag Society and Metabolic established a "geological" map showing concentrations of valuable metals in buildings to inform and guide future plans to extract second-hand materials.

42. As an example, the Excess Materials Exchange is a digital marketplace launched in the Netherlands in 2017 to find high-value reuse options for used materials.

\begin{abstract}
-BAKKER, C. et al., Products that last: product design for circular business models, TU Delft Library, Delft, 2014.
\end{abstract}

\section{- CATHOLIC CHURCH, MCDONAGH,}

S., On care for our common home: the encyclical of Pope Francis on the environment, Laudato Si', Vatican City, 2016.

- DELVA LANDSCAPE ARCHITECTS, Circular Cities: designing post-industrial Amsterdam. The case for Buiksloterham, DELVA Landscape Architects, Amsterdam, 2016.

\section{- EUROPEAN COMMISSION, Circular} Economy Action Plan. For a cleaner and more competitive Europe, Office for Official Publications of the European Communities, Brussels, 2020.

- EUROPEAN COMMISION, A European Strategy for Data, Office for Official Publications of the European Communities, Brussels, 2020.

- HARAWAY, D.J., Staying with the Trouble. Making Kin in the Chthulucene, Duke University Press, Durham and London, 2016.

\section{- HEINRICH, M., LANG, W., Materials} Passports: Best Practice Innovative Solutions for a Transition to a Circular Economy in the Built Environment, Technische Universität München, Munich, 2019.

- HU, D., et al. "Microplastics and nanoplastics: would they affect global biodiversity change?" in Environmental Science Pollution Research, 2019, 26, pp. 19997-20002.

- KORJONEN, J., et al., "Circular Economy: the concept and its limitations" in Ecological Economics, 2018, 143, pp. 37-43.

- KRAMER, K., User Experience in the Age of Sustainability: A Practitioner's Blueprint, Morgan Kaufmann, Burlington, MA, 2012.

- MARGULIS, L., SAGAN, D., What is Life?, University of California Press, Berkeley, 1995.

- MCDONOUGH, W., BRAUNGART, M., Cradle to Cradle: Remaking the Way We Make Things, North Point Press, New York, 2002.
- MIKKELSEN, K., MARTIN, R., The NeoGeneralist. Where you go is who you are, LID Publishing Ltd., London, 2016.

- NESBITT, K., Theorizing a new agenda for architecture: an anthology of architectural theory 1965-1995, Princeton Architectural Press, New York, 1996.

- OECD, Global Material Resources Outlook to 2060: Economic Drivers and Environmental Consequences, OECD Publishing, Paris, 2019.

- RAWORTH, K., Doughnut Economics: Seven Ways to Think Like a 21st-Century Economist, Penguin Random House, London, 2017.

-ŠIJAKOVIĆ, M., "Symbiotic architecture: Redefinition of recycling design principles" in Frontiers of Architectural Research, 2018, 7,1, pp. 67-69.

-SZAKY, T., Outsmart Waste: The Modern Idea of Garbage and How to Think Our Way Out of It, Berrett-Koehler Publishers, San Francisco, 2014.

UNITED NATIONS, Emissions Gap Report 2019 Global progress report on climate action, UNEP, Nairobi, 2020.

- VAN GEERT, P., "Unfolding potential as dynamic emergence. A view from the theory of complex, non-linear, dynamic systems", in The Journal of Cognitive Education and Psychology 2014, 13, 3, pp. 324-356.

-WEBSTER, K. The circular economy. A wealth of flows, Ellen MacArthur Foundation Publishing, Cowes, 2015.

-WILLIAMS, A., "Systems thinking: A review of sustainability management research", in Journal of Cleaner Production, 2017, 148, pp. 866-881.

-WORLD ECONOMIC FORUM, PLATFORM FOR ACCELERATING THE CIRCULAR ECONOMY, Harnessing the Fourth Industrial Revolution for the Circular Economy. Consumer Electronics and Plastic Packaging, Geneva, 2019.

RA. Revista de Arquitectura Núm. 22 - 2020 P. $32-45$ 